\title{
RESEÑAS \\ HARARI, YUVAL NOAH (2018). 21 LECCIONES PARA EL SIGLO XXI. BARCELONA: \\ DEBATE
}

\author{
Álvaro Asti Martínez \\ Pontificia Universidad Católica del Perú
}

El avance de la tecnología en el mundo contemporáneo está provocando una serie de transformaciones políticas, sociales y económicas que abren la posibilidad de mejorar la vida de millones de personas, pero también encarnan una serie de riesgos y amenazas, muchos de los cuales nunca antes han sido enfrentados por la humanidad y precisan de nuevas ideas para ser manejados. Acontecimientos recientes como la manipulación de la opinión pública a través de noticias falsas en redes sociales con fines electorales, o el abuso de la información de los usuarios de internet por parte de empresas y gobiernos, son temas que suelen ser discutidos bajo el sesgo de ideologías políticas e intereses contrapuestos que impiden esclarecer los hechos, entorpeciendo la búsqueda de soluciones. El libro de Yuval Noah Harari, 21 lecciones para el siglo XXI, es un intento de contribuir al debate sobre qué hacer frente a estos problemas inéditos desde una perspectiva académica.

Nacido en 1976, en Haifa (Israel), Harari realizó un doctorado en Historia por la Universidad de Oxford entre 1998 y 2002, para luego cursar estudios posdoctorales también en Historia entre 2003 y 2005, y actualmente es catedrático en el Departamento de Historia de la Universidad Hebrea de Jerusalén. Este historiador ha establecido su reputación como autor de bestsellers en el ámbito hispanohablante, como lo demuestra el hecho de que la traducción al español del libro reseñado haya sido publicada solo un mes después de la edición original en inglés. Si bien sus primeras publicaciones se concentraron en la historia militar europea durante la Edad Media, sus trabajos más recientes y por los que es más conocido, abarcan un panorama más amplio, considerando a la humanidad en todo su desarrollo histórico. Por ejemplo, su libro Sapiens (Debate, 2014), se remonta a los orígenes remotos de nuestra especie, mientras que el siguiente, Homo Deus (Debate, 2016), se adelanta a lo que podría venir en el futuro lejano. Con este cambio, Harari dejó de lado la investigación académica original para dedicarse a la divulgación científica, basándose principalmente en el trabajo de otros expertos.

21 lecciones para el siglo 21 es una colección de ensayos que, tal como se señala en la introducción, fueron en muchos casos motivados por preguntas planteadas por investigadores o lectores. Algunos de ellos fueron previamente publicados como artículos en distintos medios de prensa, pero modificados a la hora de incluirlos en el libro. Las fuentes en las que se basa son principalmente de tres tipos: artículos periodísticos, libros académicos, y artículos en revistas especializadas. La obra está dividida en veintiún capítulos, correspondientes a las "lecciones" que se mencionan en el título, los cuales a su vez se agrupan en cinco partes de entre tres y cinco capítulos. Uno de los elementos recurrentes a lo largo de la obra y que le brindan una cierta unidad a pesar de su diversidad temática es el efecto de las nuevas tecnologías y, en particular, la combinación de lo que el autor llama infotecnología y biotecnología, en distintos aspectos de la vida social e individual. Estos conceptos incluyen innovaciones tales como la inteligencia artificial, las monedas virtuales, los algoritmos informáticos configurados para adaptarse a la estructura de nuestro cerebro o los avances científicos en la prolongación de la vida humana, por nombrar algunas cosas. Todas estas técnicas, que hoy en día se encuentran todavía en pañales o aún no existen, irán a haciéndose cada vez más importantes durante las próximas décadas, por lo cual, el libro se centra en las diferentes situaciones problemáticas que estas puedan generar. 
La primera parte trata de la crisis del liberalismo. El reemplazo de los trabajadores humanos por inteligencias artificiales y el perfeccionamiento de los algoritmos informáticos hasta el punto de que conozcan a las personas mejor que ellas a sí mismas, harían que una proporción cada vez mayor de la población se vuelva política y económicamente irrelevante, y aumentaría el poder de manipulación de las empresas y la capacidad de represión de las dictaduras. Esto provocaría un socavamiento de la confianza de la población en el liberalismo y la democracia, que cohesiona gran parte del mundo en la actualidad. La segunda parte hace hincapié en la polémica sobre la globalización, ante la cual, Harari resalta que aquello que une a las sociedades contemporáneas es mucho mayor que sus diferencias culturales. Además, el aislamiento nacionalista es incapaz de resolver las nuevas crisis que se avecinan y afectan a la humanidad en su conjunto. Dentro de su crítica incluye a la religión, la cual, en tiempos modernos, sirve principalmente para justificar intereses nacionales en lugar de buscar el consenso. En consecuencia, el verdadero reto para las generaciones futuras es encontrar una forma de dejar atrás nuestras diferencias para enfrentar en conjunto los retos de un mundo irreversiblemente globalizado.

Las dos siguientes secciones tratan de temas más dispersos que los anteriores. Algunos de sus capítulos tratan de problemas vigentes, tales como el de la guerra, el terrorismo, la posverdad o una posible rebelión de los robots con inteligencia artificial contra los humanos. Sin embargo, en todos estos casos se concluye que el miedo que generan en la opinión pública es desproporcionado en relación con el grado real de peligro que representan al examinarlos objetivamente. Por otro lado, hay capítulos que se ocupan de cuestiones más filosóficas, principalmente del problema de la ética en un mundo cada vez más distanciado de Dios. Ante este dilema, Harari plantea que las personas no necesitan recurrir a ninguna religión para mantener una conducta moral, sino que el laicismo se sostiene sobre una serie de valores como la igualdad, la libertad y la verdad. Dichos valores tienen, además, la ventaja de no ser dogmáticos, a diferencia de la moral religiosa.

La quinta y última parte del libro es de un carácter más propositivo. En ella, Harari sugiere realizar modificaciones al sistema educativo para pasar de una educación centrada en la adquisición de habilidades específicas a una en la que se fomenten las habilidades generales del ser humano, de manera que la gente tenga más posibilidades de adaptarse a un entorno, en el cual, la tecnología genera constantes cambios y, por ende, inestabilidad. Por otro lado, plantea el problema de encontrar un sentido a la vida, en un contexto en que los grandes relatos que se lo daban (la religión, las ideologías políticas) se revelan como ficciones. El último capítulo, en particular, llama la atención por tener una tónica bastante diferente a la de todos los demás: se centra en la experiencia personal de Harari con la meditación, y en las maneras en que esta le brindó beneficios emocionales e intelectuales en su vida. Desde su perspectiva, esta práctica permite al ser humano aceptar la irrelevancia de su existencia sin necesidad de recurrir a ningún relato inventado.

En términos generales, este libro resulta de lectura fácil y entretenida, con un lenguaje libre de tecnicismos y una extensión relativamente corta, claramente dirigido a una audiencia amplia. Durante toda la obra podemos apreciar los conocimientos de Harari sobre los más diversos temas de historia universal, los cuales son utilizados para demostrar diversos puntos de su argumentación. Asimismo, siendo el autor un ciudadano israelita, la cultura hebrea es analizada en diversas ocasiones desde una postura autocrítica que rechaza los excesos del excepcionalismo y el nacionalismo judío. Por otro lado, hay algunos aspectos que deben ser criticados. En primer lugar, es necesario tomar en cuenta que los temas tocados exceden ampliamente el campo de especialización del historiador. Esto obliga al lector a preguntarse hasta qué punto este tiene los conocimientos suficientes para decir algo relevante sobre temas tan diversos y que abarcan tantas disciplinas. También resulta negativo que la heterogeneidad 
de los temas tratados, a veces, hace que se pierda el hilo conductor de la obra, de manera que no queda tan claro cuál es el punto al que se quiere llegar. Otro aspecto que puede resultar molesto es que algunos de los temas ya han sido tratados en los libros anteriores del autor, lo cual hace que esta nueva obra resulte algo repetitiva para quienes ya leyeron aquellos.

En definitiva, este libro es una lectura recomendada para quienes deseen un primer acercamiento a las ideas de Harari y a la problemática planteada por el impacto de las nuevas tecnologías en la sociedad, aunque definitivamente, no tiene la profundidad que podría tener una obra escrita por expertos en dicho tema. A pesar de esto, sigue siendo un ejercicio valioso de reflexión en el que todos debemos participar, ya que de eso depende que las decisiones que tomemos en el futuro nos conduzcan a una sociedad mejor. 